\title{
ANALISIS DAYA DUKUNG TANAH PADA PERENCANAAN SARANA DAN PRASARANA UMUM
}

\author{
Bambang Harimei S. \\ Laboratorium Geofisika Padat, Program Studi Geofisika, FMIPA Universitas Hasanuddin, Makassar \\ Penulis koresponden. Alamat email: bambang_harimei2004@yahoo.com
}

\begin{abstract}
Abstrak
Telah dilakukan penelitian daya dukung tanah pasa perencanaan sarana dan prasana umum, metode yang digunakan dalam penelitian adalah DCP dan CBR. Adapun hasilnya sebagai berikut; Lokasi sampel DCP 1 dan DCP 2 mempunyai nilai qc berkisar antara $20-24 \mathrm{~kg} / \mathrm{cm}^{2}$, Mv berkisar 0,025 $0,056 \mathrm{~cm}^{2} / \mathrm{kgdan} \alpha$ sebesar 1,5 hingga 4 serta nilai CBR masing-masing sampel lebih besar dari $2 \%$. Nilai-nilai parameter ini. memperlihatkan sifat fisis dari sampel DCP 1 dan DCP 2 adalah low plasticity loam.
\end{abstract}

Kata kunci: DCP, BCR, Plastisitas Rendah

\begin{abstract}
The research has been carried out to investigate the carrying capacity of plan of public facilities and infrastructure, the method used in the research is DCP and CBR. The results are as follows; The sample locations of DCP 1 and DCP 2 have qc values ranging between 20-24 kg/ $\mathrm{cm}^{2}$, Mv ranges from $0.025-0.056 \mathrm{~cm}^{2} / \mathrm{kg}$ and $\alpha$ of 1.5 to 4 and the CBR value of each sample is greater than $2 \%$. The values of these parameters. Shows the physical properties of the DCP 1 and DCP 2 sample is the low plasticity loam.
\end{abstract}

Keywords: DCP, BCR, Low plasticity

\section{Pendahuluan}

Dewasa ini ruang terbuka hijau pada perkotaan dirasakan perlu untuk diadakan. Untuk maksud pengadaan ruang terbuka hijau Pemkab Kutai Kartanegara membangun sarana dan prasarana umum. Nama rencana pembangunan kawasan promenade terletak. Salah satu rencana kegiatan adalah pembangunan area bermain bagi anak-anak. Agar pembangunan yang akan dibangun bisa kuat dan kokoh perlu kiranya, diteliti tentang daya dukung tanah bawah permukaan pada tempat pembangunan.
Selanjutnya dilakukan analisis Geoteknik (Mekanika Tanah dan Teknik Pondasi) yang benar dan baik, sangat diperlukan data-data tanah (soil test) bawah permukaan yang lengkap dan akurat. Datadata ada yang diperoleh langsung dari survey geoteknik lapangan dan ada yang diperoleh langsung dari uji laboratorium terhadap contoh tanah yang diambil dari bawah permukaan melalui boring.

Banyak metode yang digunakan dalam melakukan studi tentang tanah di lapangan, antara lain; dapat berupa interpretasi foto udara dan remote sensing, metode 
geofisika, metode geolistrik, sumur uji (test pit) pemboran (boring) (dangkal sampai dalam), uji penetrometer (uji sondir, Cone Penetration Test -CPT), uji Vane Shear Test, Pocket Penetometer Test, California Bearing Test (CBR) dan lain lain. Dalam penelitian ini menggunakan CPT dan CBR. Pemboran tanah/boring dan sondir (CPT) adalah pekerjaan yang paling umum dan akurat untuk tanah berlempung dalam survey geoteknik lapangan.

Seperti dijelaskan pada paragraf di atas, Analisis daya dukung Tanah digunakan untuk mengetahui keadaan suatu tanah yang akan digunakan tempat berdirinya suatu bangunan. Hasilnya data-data daya dukung tanah menerima beban di atas sebagai bangunan.

Data ini, dapat digunakan dalama menentukan sruktur bangunan, tipe pondasi dan lain-lainnya sesuai dengan sifat-sifat yang dimiliki tanah dilokasi "Perencanaan Pengembangan Kawasan Promenade Tenggarong". Hal tersebut sangat penting untuk memunjang segi ekonomis, segi keselamatan baik bangunan, pemakain maupun pekerja ya ada. Dalam memilih jenis pondasi haruslah berdasarkan daya dukung tanah. Hal ini dikarena, fondasi berfungsi untuk menyalurkan beban secara langsung pada bagian dalam lapisan tanah. Ada berapa macam lapisan tanah, dalam hal ini diambil dua lapisan tanah.

Pertama lapisan tanah keras. Lapisan keras mampu menahan beban akibat beban di atas lapisan, Ke dua lapisan tanah lunak, Jenis lapisan ini beban akibat beban struktur didistribusikan sampai ke lapisan dalam permukaan di bawah struktur. Dalam mengukur daya dukung tanah digunakan Peralatan Dyamic Cone Penetrometer (DCP). Dynamic Cone Penetrometer adalah alat yang digunakan untuk mengukur daya dukung tanah dasar langsung di tempat (in situ).
Daya dukung tanah asar tersebut diperhitungkan berdasarkan pengolahan atas hasil test DCP yang dilakukan dengan cara mengukur berapa dalam $(\mathrm{mm})$ ujung konus masuk ke dalam tanah dasar tersebut setelah mendapat tumbukan palu geser pada landasan batang utamanya. $D C P$ merupakan peralatan yang terdiri dari bermacam-macam tipe, dengan prinsip cara penggunaan peralatan tersebut sama. $D C P$ telah digunakan pada studi tentang Transportasi di laboratorium mempunyai spesifikasi berat palu pemukul $8 \mathrm{~kg}$, tinggi jatuh palu $575 \mathrm{~mm}$, sudut cone $60^{\circ}$, diameter $20 \mathrm{~mm}$.

Korelasi antara banyaknya tumbukan dan penetrasi ujung conus dari alat DCP ke dalam tanah akan memberikan gambaran kekuatan tanah dasar pada titik-titik tertentu. Makin dalam konus yang masuk untuk setiap tumbukan artinya makin lunak tanah dasar tersebut. Uji sondir atau dikenal dengan uji penetrasi kerucut statis banyak digunakan di Indonesia. Pengujian ini merupakan suatu pengujian yang digunakan untuk menghitung kapasitas dukung tanah. Nilai-nilai tahanan kerucut statis atau hambatan konus ( $q c$ ) yang diperoleh dari pengujian dapat langsung dikorelasikan dengan kapasitas dukung tanah (Hardiyatmo, 2002). Pada uji sondir, terjadi perubahan yang kompleks dari tegangan tanah saat penetrasi sehingga hal ini mempersulit interpretasi secara teoritis. Dengan demikian meskipun secara teoritis interpretasi hasil uji sondir telah ada, dalam prakteknya uji sondir tetap bersifat empiris..

Keuntungan uji sondir yaitu: (1) cukup ekonomis dan cepat, dan (2) dapat dilakukan ulang dengan hasil yang relatif hampir sama.

Hubungan antara qc sondir dengan kompresibilitasnya dikembangkan melalui riset yang dilakukan oleh Thomas Smith 
(1968). Hubungan yang diperoleh dirumuskan ke dalam rumus berikut:

$$
\mathrm{C}=\alpha\left(\frac{q_{c}}{\sigma}\right)
$$

dengan $\mathrm{C}$ adalah Kompresibilitas, $\alpha$ adalah nilai koefisien yang bergantung dari nilai qc tanah, qc adalahnilai tahan ujung sondir, dan $\sigma$ adalah Overburden effective pressure.

Kompresibilitas dengan tahanan ujung sondir, diturunkan degan rumus koefisien kemampatan volume berdasarkan nilai qc sondir, dan dikembangkan oleh Gardner (1975), yakni:

$$
\alpha=\left(\frac{1}{m_{v q_{c}}}\right)
$$

dengan mv adalah koefisien kemampatan volume $\left(\mathrm{cm}^{2} / \mathrm{kg}\right), \alpha$ adalah koefisien yang bergantung pada nilai qc, dan qc adalah tahanan ujung sondir $\left(\mathrm{kg} / \mathrm{cm}^{2}\right)$.

Pengujian dengan menggunakan alat DCP akan menghasilkan data tanah. Selanjutnya, dilakukan pengujian di laboratorium untuk mendapatkan harga CBR. Besarnya nilai CBR tanah akan menentukan ketebalan lapis keras yang akan dibuat sebagai lapisan perkerasan diatasnya. Makin tinggi nilai CBR tanah dasar (subgrade ) maka akan semakin tipis lapis keras yang dibutuhkan dan semakin rendah suatu nilai CBR maka semakin tebal lapis keras yang dibutuhkan. Ada 2 macam pengukuran CBR yaitu:

1. Nilai CBR untuk penekanan pada penetrasi $0,254 \mathrm{~cm}(0,1$ ”) terhadap penetrasi standar yang besarnya 70,37 $\mathrm{kg} / \mathrm{cm}^{2}$ ( $1000 \mathrm{psi}$ )

Nilai CBR $=\left[\frac{P I}{70,37}\right] x 100 \%$

2. Nilai CBR untuk tekanan pada penetrasi $0,508 \mathrm{~cm}(0,2$ ") terhadap tekanan standar yang besarnya 105,56 $\mathrm{kg} / \mathrm{cm}^{2}$ ( $1500 \mathrm{psi}$ )

Nilai CBR $=\left[\frac{P 2}{105,56}\right] \times 100 \%$
Menurut Head (1986) nilai CBR dilaporkan dengan aturan berikut ini :

1. untuk nilai CBR dibawah 25, $3 \%$ dilaporkan $25 \%$.

2. untuk nilai CBR antara $30 \%-100 \%$ dibulatkan ke $5 \% .42 \%$ dilaporkan menjadi $40 \%$.

3. untuk nilai CBR diatas $100 \%$ dibulatkan ke $10 \%, 104 \%$ dilaporkan menjadi $100 \%$.

\section{Metode Penelitian}

Pada penelitian ini, terdiri dari dua phase, phase pertama yaitu pengujian sifat sifat fisis tanah : kadar air, berat jenis, atternberg limit dan analisa butir. Phase kedua yaitu pengujian sifat mekanis tanah lempung yaitu: pemadatan, DCP dan CBR.

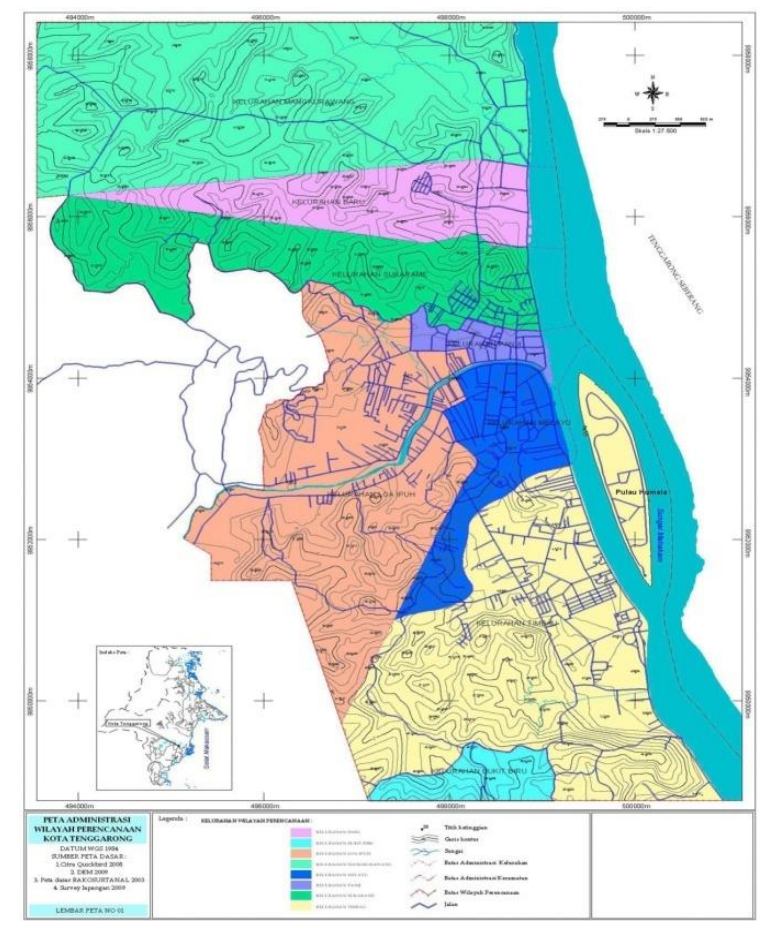

Gambar 1. Peta administrasi lokasi penelitian

Setelah dilakukan pengambilan data di dapatkan nilai qc, Mv, $\alpha$ dan nilai CBR di masing titik pengambilan sampel. Adapun hasil dari pengolahan data dapat di lihat Tabel 1. 


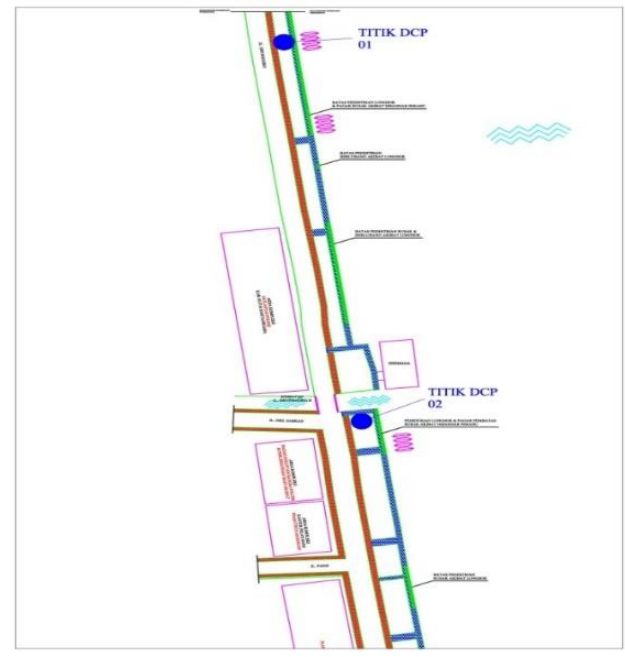

Gambar 2. Lokasi pengambilan sampel
Setelah melakukan langkah selanjutnya menentukan hubungan antara Kedalaman dan jumlah kumpulan, selain itu, ditentukan hubungan antara DCP dan CBR di setiap pengambilan sampel. Adapun ahsil dapat di liahat pada Gambar 3 . Analisis selnjutnya dilakukan pada titik sampel DCP 2, adapun hasilnya dapat di lihat pada Gambar 4. Pada umumnya gambar 3 dan 4 memberi informasi sifat fisis tanah pada daerah penelitian bahwa untuk mencapai kedalaman yang diinginkan diperlukan jumlah pukulan yang banyak.(lihat Gambar 3a dan 4a).

Tabel 1 Hasil Pengolahan Data

\begin{tabular}{cccccc}
\hline No. & Sampel & $\begin{array}{c}\mathbf{q c} \\
(\mathbf{k g} / \mathbf{c m} 2)\end{array}$ & $\begin{array}{c}\mathbf{M v} \\
(\mathbf{c m} \mathbf{2} / \mathbf{k g})\end{array}$ & $\mathbf{A}$ & $\begin{array}{c}\text { CBR } \\
(\mathbf{\%})\end{array}$ \\
\hline 1 & DCP 1 & $20-23$ & $0,025-0,046$ & $2,12-3,11$ & 2,59 \\
\hline 2 & DCP 2 & $21-24$ & $0,028-0,056$ & $1,21-2,12$ & 2,28 \\
\hline
\end{tabular}

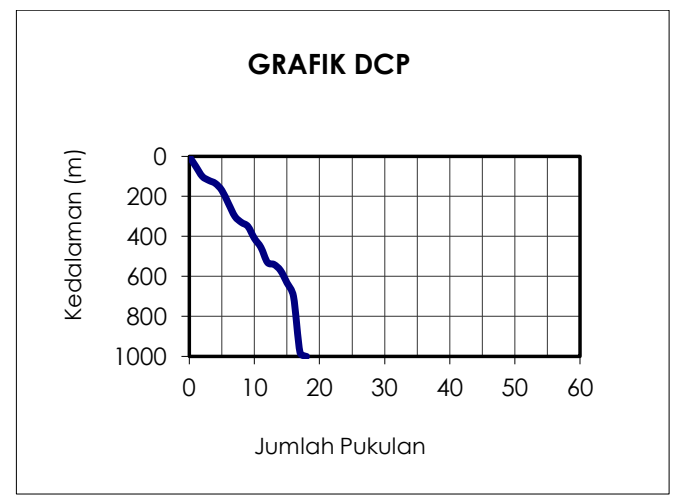

(a)

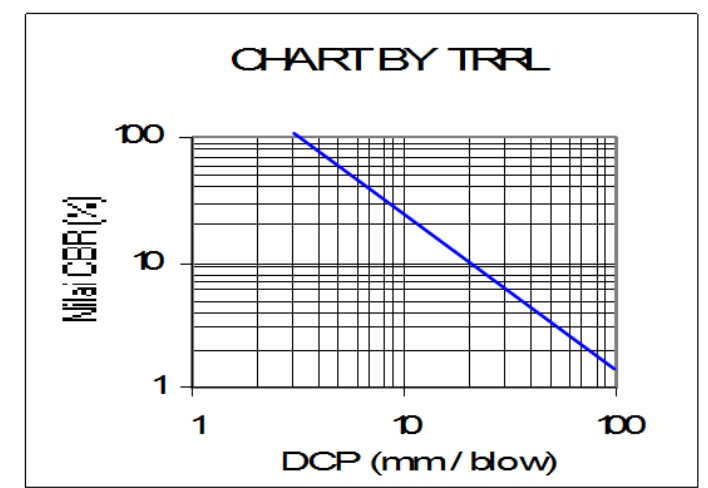

(b)

Gambar 3. (a) Hubungan antara kedalaman dan jumlah pukulan, sedangkan Gambar b menunjukkan hubungan antara nilai CBR dan DCP.

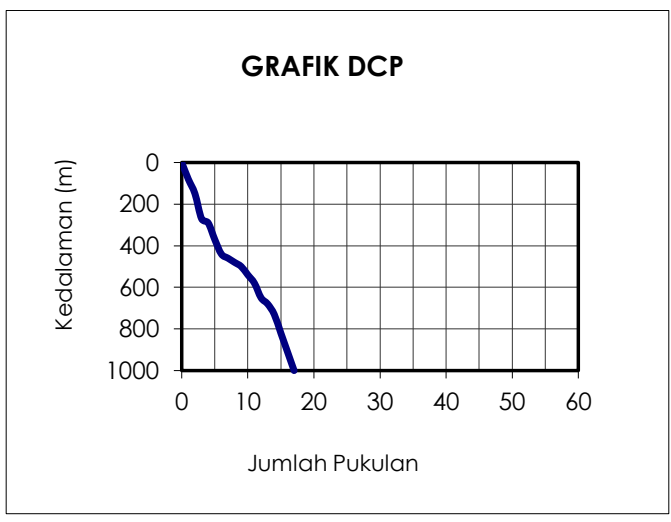

(a)

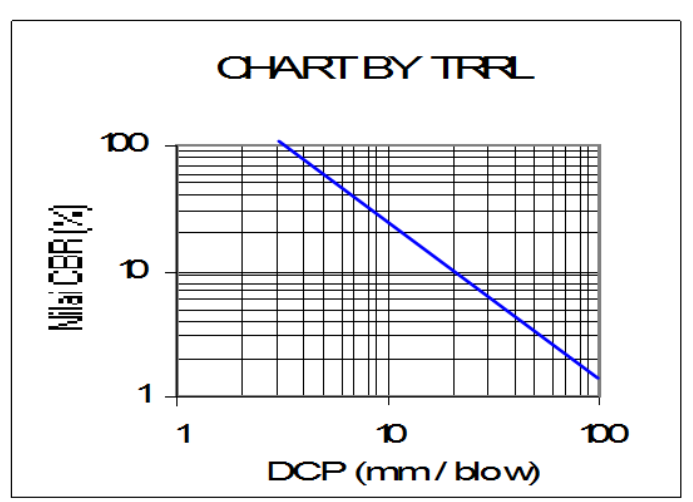

(b)

Gambar 4. (a) Hubungan antara kedalaman dan jumlah pukulan, (b) hubungan antara nilai CBR dan DCP. 


\section{Hasil dan Pembahasan}

Harga CBR dihitung pada harga penetrasi 0 dan $20 \mathrm{~m}$, dengan cara membagi beban pada penetrasi ini masing-masing dengan beban sebesar 3000 dan 4500 pound. CBR adalah perbandingan antara beban penetrasi suatu bahan terhadap beban standar dengan kedalaman dan kecepatan penetrasi yang sama. Pada Gambar 3. Huruf $b$ menunujukan CBR dengan DCP berbanding lurus, hal ini dapat dilihat nilai CBR berawal dari $100 \%$ dan turun sampai pada $1,5 \%$. Hal yang sama pada penuruanan grafik di alami DCP 5, 6 $\mathrm{mm} / \mathrm{blow}$ dan berakhir $100 \mathrm{~mm} / \mathrm{blow}$. Sedangkan Nilai qc pada titik sampel 20 $23 \mathrm{~kg} / \mathrm{cm} 2$ dan Mv sebesar 0,025 - 0,046 $\mathrm{cm} 2 / \mathrm{kgdan} \alpha$ sebesar 1,5 hingga 4Nilainilai dari parameter ini apabila dikonfirmasikan penelitian dari Gardner (1975) menyebutkan bahwa sifat fisis dari sampel DCP 1 adalah ML - Low plasticity loam.

Pada Gambar4. Untuk mencapai kedalaman $100 \mathrm{~m}$ diperlukan jumlah pukulan lebih dari 20 pukulan, hubungan CBR dan CDP dapat dilihat pada Gambar 4b. nilai CBR berawal dari $99 \%$ dan turun sampai pada $2,1 \%$. Hal yang sama pada penurunan grafik dialami DCP 6,1 $\mathrm{mm} / \mathrm{blow}$ dan berakhir $98 \mathrm{~mm} /$ blow. Sedangkan Nilai qc pada titik sampel 21 $24 \mathrm{~kg} / \mathrm{cm} 2$ dan $\mathrm{Mv}$ sebesar 0,028 - 0,056 $\mathrm{cm}^{2} / \mathrm{kg}$ dan $\alpha$ sebesar 1,5 hingga 4Nilainilai dari parameter ini apabila dikonfirmasikan penelitian dari Mitchell dan Gardner (1975) menyebutkan bahwa sifat fisis dari sampel DCP 1 adalah ML Low plasticity loam.

\section{Kesimpulan}

Dari hasil dan pembahasan dapat di tarik kesimpulan antara lain ;

1. Lokasi titik DCP 1 dan DCP 2 mempunyai nilai qc berkisar antara 20 -
$24 \mathbf{~ k g} / \mathbf{c m}^{2}, \mathrm{Mv}$ berkisar 0,025 - 0,056 $\mathrm{cm}^{2} / \mathrm{kg}$ dan $\alpha$ sebesar 1,5 hingga 4.Serta masing-masing sampel mempunyai nilai CBR lebih besar dari $2 \%$.

2. Nilai-nilai dari parameter point 1 . apabila dikonfirmasikan penelitian dari Mitchell dan Gardner (1975) menyebutkan bahwa sifat fisis dari sampel DCP 1 adalah ML - Low plasticity loam.

\section{Saran}

1. Pemilihan pondasi yang akan dipakai disesuaikan dengan peruntukan bangunan dan beban yang akan didistribusikan ke lapisan tanah dasar.

2. Sebelum melakukan pekerjaan konstruksi, sebaiknya terlebih dahulu dilakukan pengujian boring.

\section{Daftar Pustaka}

ASTM. 2003. Annual Book of ASTM Standard, Section 4 Volume 4.08. Soil and Rock.

Gardner 1975, "Bearing Capacity of Shallow Foundations from CPT Data." 3rd Iranian International Conference on Geothechnical Engineering and Soil Mechanics. Iran. 93 - 97.

Hardiyatmo, H.C. 2002. Mekanika Tanah I. Yogyakarta: UGM Press.

Lambe, T.W. and Whitman R.V. 1969. Soil Mechanics. New York: John Wiley \& Sons.

Ricahrd, P.W. 2009. Bearing Capacity of Shallow Footing for NonGeotechnical Enginers. PDHengineer.com .

Smith Thomas 1090 Advance Soil Mechanics. PWS - KENT Publishing Company Advance 